\title{
EL ANTÓLOGO COMO AUTOR Y LA INTERPRETACIÓN DE LAS OBRAS ESCRITAS POR MUJERES: LECTURAS FIRMADAS DE JOSEP MARIA CASTELLET ${ }^{1}$
}

\author{
Raquel Fernández Menéndez \\ Universidad de Oviedo \\ Oviedo, España \\ fmraquel@uniovi.es
}

\begin{abstract}
RESUMEN / ABSTRACT
En este artículo se propone un estudio de las antologías poéticas a partir de los principales debates teóricos en torno a la lectura desarrollados por los estudios literarios y por la teoría literaria feminista. Este marco permite prestar atención a las relaciones de apropiación que el antólogo/a establece con los poemas seleccionados, perspectiva que ha sido frecuentemente pasada por alto al analizar estas selecciones como meras recopilaciones de poemas. Como se comprobará a partir de la producción antológica de Josep Maria Castellet, este enfoque aporta interesantes claves para abordar las relaciones de las escritoras con las antologías, ya que permite profundizar en la construcción del sentido de los textos incluidos a través de la lectura y de la fragmentación de los conjuntos originales.
\end{abstract}

PALABRAS ClAVE: lectura, antologías, teoría feminista, poesía española contemporánea, Josep Maria Castellet.

1 Este trabajo se enmarca en el Programa Severo Ochoa (referencia PA-17-PF-BP16126) de Ayudas predoctorales para la investigación y la docencia del Gobierno del Principado de Asturias. 
The Anthologist as an Author and the Reading of Literature by Women: JoseP Maria Castellet's 'Signature Pieces'

This article proposes a study of poetic anthologies from theories of reading that have been proposed in literary studies and feminist literary theory. This conceptual framework allows to pay attention to the relationships of appropriation that the anthologist establishes with the selected poems, a perspective that has frequently been disregarded when these books are considered as mere selections of poems. As the analysis of Josep Maria Castellet's anthologies shows, this point of view provides us with interesting keys to the study of the relationships between women writers and anthologies, as it addresses the problem of making sense through reading and fragmentation from the original ensemble.

KEYWords: Reading, anthologies, feminist theory, Spanish Contemporary Poetry, Josep Maria Castellet.

Recepción: 10/03/2020

Aprobación: 24/06/2020

\section{LECTURA Y REESCRITURA EN LA ANTOLOGÍA POÉTICA}

En 1985, Claudio Guillén proponía un estudio de las antologías que reparara en el ejercicio de lectoescritura emprendido por el antólogo al definirlas como "una forma colectiva intratextual que supone la reescritura o reelaboración, por parte de un lector, de textos ya existentes mediante su inserción en conjuntos nuevos" (Guillén 413). El eminente comparatista insistía así en un rasgo frecuentemente pasado por alto al estudiar estos libros: la intervención en las obras ajenas que el antólogo lleva a cabo a través de la selección, tarea que excede con mucho el estatuto de simple compilador que, tradicionalmente, se le ha atribuido. En efecto, el DRAE define "antología" como una "colección de piezas escogidas de literatura, música, etc.”, definición a la que, tal y como recuerda José Francisco Ruiz Casanova, habría que añadir el matiz subrayado en la etimología del término: la "acción de elegir o seleccionar flores" (Ruiz Casanova 34). La diferencia reside así en dónde se sitúe el foco de interés: en el sujeto de la actividad o en su objeto, aspecto igualmente destacado por Carlos Guzmán Moncada al distinguir "antología" de "florilegio": "Aunque nacidos de la misma metáfora, los términos 'antología' y 'florilegio' han hecho brotar, sin embargo, sentidos encontrados, por cuanto el yo recojo antológico supone un valor selectivo que el recopilador de florestas, en principio, no tiene" (Guzmán Moncada 35).

La distancia entre ambos términos revela asimismo la necesidad de acotar este trabajo a la literatura contemporánea, puesto que, en España, a finales del 
siglo XIX, el término "antología" comenzará a desplazar a los de "florilegio" o "parnaso" (Ruiz Casanova 35), un cambio que tendrá importantes consecuencias en el asentamiento de los paratextos que las caracterizan en la actualidad y en el papel desempeñado en ellos por el antólogo. De ello daba buena cuenta Marcelino Menéndez Pelayo al definir las selecciones anteriores al siglo XVIII como pertenecientes "al género de colecciones fortuitas" (Menéndez Pelayo VII) en su ambiciosa Antología de poetas líricos castellanos (1890). Frente a la "acumulación" (Ruiz Casanova 121) a la que parecía aludir el sintagma empleado por el filólogo santanderino, en la época contemporánea, la antología constituirá, retomando la óptica de Guillén, una especie de lectura firmada en la que, como añadirá José Francisco Ruiz Casanova, sería posible distinguir "rasgos estilísticos" (22) en la muestra escogida o en los paratextos (citas, prólogos, iconografía) que las definen en su forma actual y que atestiguan una marcada huella del signatario. En sus palabras, "el antólogo se apropia de unos textos (de su lectura) y promueve el rescate del olvido mediante la reedición y la singularización del poema, esto es, como una obra nueva" (Ruiz Casanova 38). Desde esta perspectiva, contra la tendencia generalizada a prestar atención únicamente a la nómina propuesta y a los olvidos que de ella se extienden, este planteamiento supondría un primer paso para comprender la coherencia de la antología como libro (Ruiz Casanova 55-57) y, en consecuencia, para reflexionar sobre las estrechas fronteras entre lectura y escritura que rigen su preparación y que resultan determinantes para la interpretación y la recepción de las obras incluidas.

A pesar de que ha existido un notable interés por las antologías en la crítica académica española, la mayor parte de las investigaciones desarrolladas hasta el momento se han centrado en exclusiva en su influencia en la posterior conformación de los cánones (Champeau y Ly; García, A la ética; García, El compromiso). Ciertamente, se trata de documentos de gran relevancia para comprender el posterior devenir de la historia de la literatura, una realidad que Alfonso Reyes constataba en la temprana fecha de 1930 al señalar que "toda antología es ya, de suyo, el resultado de un concepto sobre una historia literaria" (Reyes 112). Tal y como vislumbraba el ensayista mexicano, la nómina de poetas y poemas propuestos en cada uno de estos libros trata de dar respuesta a la necesidad, común en todas las culturas y naciones (Guillén 417), de clasificar y jerarquizar lo escrito de acuerdo con una determinada identidad nacional que, en este caso, se proyecta en el individuo que propone la muestra (Sullà 11). Esta cuestión se desarrolla con profundidad en trabajos como los de Pozuelo Yvancos (125-127) o Romero Tobar (56- 
59), y, posteriormente, en los de especialistas que trataron de documentar la historia de la literatura española a través de las antologías centradas en sus distintos períodos (García, A la ética; García, El compromiso). Sin embargo, recuperar la figura del antólogo como lector y escritor de un nuevo conjunto permite una más precisa aproximación a la constitución de una autoridad que, efectivamente, puede determinar las prácticas de lectura del resto de la comunidad (Guillén 413) y, a la vez, cuestionar un concepto de autoría basado únicamente en el principio de originalidad.

Entendida como una lectura firmada, la antología no solo parece condicionar el devenir de la literatura en la historia, sino que obliga necesariamente a reflexionar en torno al papel de la interpretación en la articulación de nuevos textos y en el sentido que el nuevo conjunto adquiere en su contexto institucional. Como entiende José Francisco Ruiz Casanova (23), mientras que en las artes plásticas la originalidad del collage ha sido aceptada hace décadas, generalmente, la crítica literaria aún no se ha enfrentado a las antologías como una obra inédita, $\mathrm{y}$, por tanto, no se ha asumido que su análisis debe superar la inclinación a señalar únicamente las inclusiones y las exclusiones de determinados nombres y textos. Bien es cierto que no en todas las antologías se aprecia un mismo grado de participación del antólogo -las encargadas por las instituciones académicas o por la administración se caracterizan, por lo general, por una autoría colectiva y, en consecuencia, tienden a apartarse de este principio-, sin embargo, el reconocimiento de esta figura ha sido una tendencia creciente en la literatura contemporánea que, sin duda, ha estado favorecida por la notable atención que la prensa cultural ha prestado a la publicación de estos libros (Ruiz Casanova 199-202). De este modo, sin perder de vista referencias como las anteriores, fundamentales en su articulación de una utilísima historia de las antologías poéticas en España, las propuestas de Guillén y Ruiz Casanova permiten retomar algunos de los debates teóricos en torno a la lectura producidos a lo largo del siglo xx con el fin de plantear una nueva perspectiva para el estudio de estos volúmenes en los que el antólogo se manifiesta a través de diversas "piezas de autor" (Kamuf) que sitúan en un primer plano la actividad de selección y reescritura (Ruiz Casanova 34-35).

Esta óptica resultaría especialmente fecunda para abordar las relaciones de las escritoras con las antologías poéticas y los órganos de reconocimiento. Reparar en la actividad de lectoescritura del antólogo supondrá no solo constatar la clara exclusión que ha pesado sobre las obras de autoría femenina en las selecciones contemporáneas, ampliamente documentada por la crítica 
literaria feminista (Russ), y, más recientemente, por investigaciones de carácter filológico desarrolladas en el ámbito de la literatura española (Payeras Grau, Espejos 39-42; Alonso Valero 97-105; Moreno), sino de analizar cómo el sentido de los textos se encuentra intervenido por las prácticas de lectura, selección y reescritura del antólogo. Asumiendo la posición de "otredad" ocupada por las mujeres en la cultura (Zavala 28), se trata de prestar atención a la doble tarea de lectura y escritura que define al autor del conjunto y, consecuentemente, esclarecer qué procedimientos ligados a la división entre los sexos resultan determinantes en esta lectura firmada que, tal como se ha señalado, puede llegar a funcionar con el paso del tiempo como un modelo para la historia de la literatura ${ }^{2}$.

Con este objetivo, en primer lugar, se revisarán algunas de las aportaciones teóricas fundamentales sobre la lectura para reconsiderar la antología como un conjunto de nueva creación determinado por el relativo grado de originalidad de los procesos interpretativos. Seguidamente, a partir de las aportaciones de la crítica literaria feminista, se analizarán las implicaciones de este cambio de perspectiva al estudiar las relaciones que las obras escritas por mujeres entablan con el concepto de "selección", eje de las propuestas de Guillén y Ruiz Casanova. Las antologías Veinte años de poesía española (1960) y Nueve novísimos poetas españoles (1970) de Josep Maria Castellet servirán para mostrar la potencialidad de este nuevo enfoque para la investigación en torno a los conceptos de género y autoría en literatura española contemporánea.

\section{LA ATENCIÓN AL LECTOR EN LA TEORÍA LITERARIA CONTEMPORÁNEA: EL ANTÓLOGO COMO AUTOR}

En las últimas décadas del siglo xx, las prácticas de lectura fueron el objeto central de numerosas investigaciones llevadas a cabo desde los estudios literarios, que se ocuparon, fundamentalmente, de la problemática de los procesos de producción del sentido (Littau 3-10). En este contexto, se ha atribuido a la obra de Roland Barthes la popularización de la tendencia en

\footnotetext{
De acuerdo con esta premisa, se ha optado por no desdoblar el género de los sustantivos "antólogo", "autor" o "lector" con el fin de subrayar hasta qué punto ha sido pasada por alto la naturaleza sexuada de estas prácticas culturales en los estudios literarios, una cuestión que será recuperada en la tercera parte de este trabajo.
} 
la teoría contemporánea a privilegiar el papel del lector (Culler 33; Littau 10). En Crítica y verdad (1966), Barthes aproximaba ya lectura y creación al definir la labor del crítico como "un acto de plena escritura" (Barthes, Crítica 48), con lo que, con este ensayo, no solo se inauguraba una influyente aproximación a esta actividad, sino que, además, se ponía en cuestión la crítica basada en el autor y la obra al entrever en la interpretación de los textos un acto creativo que trasciende el sentido otorgado a los mismos por el escritor. Esta línea conceptual alcanzaría su máxima expresión en su trayectoria con la publicación del influyente artículo "La muerte del autor" (1968), en el que el semiólogo francés defendería la existencia de una escritura autónoma cuyo sentido dejaba de depender de la voluntad de su autor, en quien la crítica positivista había hecho recaer todo el significado de la obra (Barthes, susurro 36). El texto se convertía así en "un espacio de múltiples dimensiones en el que se concuerdan y se contrastan diversas escrituras, ninguna de las cuales es la original", y quedaba definido como "un tejido de citas provenientes de los mil focos de la cultura" (Barthes, susurro 69). En consecuencia, a partir del funcionamiento de una serie de códigos, la lectura adquiría la capacidad de articular significados en cuya formación la figura del autor desaparecería (Barthes, susurro 37).

En Estados Unidos, la impronta del pensamiento de Roland Barthes sobre la lectura se reflejó en el progresivo abandono del $\mathrm{New}_{\mathrm{Criticism}}^{3}$, tendencia que había aspirado a la objetividad de la crítica al asumir la autosuficiencia de los textos y rechazar tanto la intencionalidad del autor como la subjetividad de su intérprete como fuentes del sentido, en favor de trabajos que centraron su atención en la respuesta del lector (Viñas Piquer 404; Lentricchia 131; Littau 104). De este modo, los primeros ensayos de Harold Bloom se aproximaron a los presupuestos de la Nouvelle Critique al acercar los procesos de interpretación y de escritura. A través de la noción de "misreading" ("lectura incorrecta"), Bloom hacía referencia a cómo las interpretaciones desviadas

3 La explicación inmanente del sentido de las obras defendida por el New Criticism será progresivamente superada también en Alemania, donde, a finales de la década de los sesenta se publicaron algunos de los trabajos más influyentes de la denominada "Estética de la recepción". Esta tendencia no solo prestará atención a la participación del lector/a en la obra, sino que avanzará planteamientos que posteriormente tendrán una gran influencia en los estudios literarios, entre ellos, el papel del público en la gestación de los textos, la vinculación del reconocimiento del autor/a con la interpretación de la obra o la problemática identificación entre personaje y lector/a (Rothe 14-16). 
del original constituían el principal motor de la formación del canon, y, por ello, la escritura devenía una forma de revisionismo que dotaba al autor de la originalidad necesaria para separarse de sus predecesores. Asimismo, este concepto le permitía al profesor de Yale poner en cuestión la distancia entre el poeta y el crítico, ya que, desde su perspectiva, la labor de ambos no difiere en el tipo de práctica llevada a cabo (el acto de malinterpretar una obra determinada), sino en el grado, que precisa que, en las obras de creación, las interpretaciones erróneas resulten más drásticas (Bloom, Anxiety 94-95). La importancia otorgada por Bloom a este proceso le servía para concluir que "no hay textos, sino solo relaciones entre textos" (Bloom, Map 3) que dependen de una actividad crítica estrechamente ligada a la escritura, perspectiva cercana a la metáfora del "tejido de citas" propuesta por Barthes.

Estas hipótesis sobre la agencia del lector y, muy especialmente, sobre la escritura del crítico permiten considerar la tarea del antólogo al margen de los tópicos sobre la falta de originalidad que subyace a la elección de nombres y textos (Ruiz Casanova 23). En cierto modo, el antólogo "escribe la lectura" (Barthes, susurro 35) al plasmarla sobre el papel y al proponer, a través de su localización en un nuevo conjunto, sentidos alternativos de los textos seleccionados. Recurriendo a la noción de Bloom, su "malinterpretación" de las obras escogidas queda singularizada a través de los paratextos (prólogos, citas, notas autobiográficas e iconografía, entre otros) y, especialmente, de la firma que da coherencia al conjunto, elementos que lo convierten en un "escritor de segundo grado" (Guillén 413). Consecuentemente, el éxito de su lectura, sobre el que se ha insistido al hablar de la estrecha relación entre canon y antología, depende en gran medida de los rastros de una autoría que convierten al nombre localizado en la cubierta en claro indicador de la autoridad para influir, con su interpretación, en la del resto, una dinámica similar en cierto modo a la noción de "ansiedad de la influencia" de Bloom, caracterizada por la "lectura errónea" emprendida por los autores destinados a pervivir en el tiempo (Bloom, Anxiety 5).

Esta cuestión resulta fundamental a la hora de estudiar la antología como una lectura particular que, con el paso del tiempo, se convierte en modelo, ya que la firma que la sustenta impide considerar al antólogo como uno más entre los lectores. Generalmente, quien emprende la tarea de organización de lo escrito que caracteriza a estas colecciones pertenece a un grupo privilegiado en la esfera cultural, bien sea al ámbito académico, al periodístico o al creativo, ya que el reconocimiento del nombre con anterioridad a la publicación de la antología resulta determinante para dotar de legitimidad 
al libro. En este sentido, es necesario tener en cuenta que muchos de los trabajos que se han ocupado de la respuesta del lector han incidido en la necesidad de prestar atención a la disimetría entre la tarea del lector común y aquellas interpretaciones reconocidas como válidas, que promoverían un cambio en el estatuto de canonicidad de los textos. Desde esta perspectiva, comprender por qué ciertas "malinterpretaciones" tienen un mayor éxito implica, necesariamente, valorar el estrecho vínculo entre lectura y autoridad que Bloom parece pasar por alto.

Por este motivo, el concepto de "comunidad interpretativa", acuñado por Stanley Fish (Text 167-173), resulta aquí fundamental. Fish destaca, como Harold Bloom, la cercanía entre las prácticas de lectura y escritura al observar que son los actos interpretativos los que constituyen la fuente del texto y no al revés (Fish, Text 167), pero introduce la problemática de la sistematicidad que caracteriza a la producción del sentido, un factor determinante para comprender por qué no todas las lecturas son consideradas igualmente válidas. Este término identifica el funcionamiento de grupos lectores que comparten una serie de convenciones a la hora de dotar de significado a las obras literarias, de modo que la interpretación se produce siempre en contextos concretos y fuertemente institucionalizados, y, por lo tanto, precede a la lectura, moldeándola (Fish, Text 168). Esta perspectiva permite, por un lado, enmarcar la selección del antólogo en los márgenes aceptados por la comunidad a la que pertenece, y comprender por qué, frecuentemente, la taxonomía propuesta coincide con la de otras selecciones que se ocupan de la misma etapa artística; por otro, favorece que, en algunas ocasiones, su lectura y consiguiente selección disientan de los modelos existentes y propongan cambios en el seno de la comunidad, ya que la estabilidad que define a estos grupos depende en gran medida de la variabilidad que experimentan las prácticas adoptadas con el paso del tiempo (Fish, Text 167-168).

La estrecha relación con las dinámicas de la "comunidad interpretativa" a la que pertenece convierte al antólogo en el "lector informado" de Fish (literatura 124), un término que recuerda al "superlector" con el que Claudio Guillén (413) lo identifica, y que subraya lo legítimo de su lectura y reescritura ${ }^{4}$.

\footnotetext{
En este sentido, otra posible orientación de este trabajo podría apoyarse en la teoría de Pierre Bourdieu. El sociólogo comprende "toda apropiación de una obra de arte" como "una relación de distinción" (267), esto es, como un medio de legitimación de las clases dominantes apoyado en los mecanismos de formación del gusto. En consecuencia, la "apropiación" que caracteriza al antólogo exigiría "unas disposiciones y unas competencias
} 
Sin embargo, el peso que ejerce la comunidad no resta importancia a la firma que da cohesión al conjunto y que singulariza al sujeto que selecciona con los rasgos que han sido históricamente atribuidos al autor. En este sentido, es necesario recuperar las aportaciones teóricas sobre el lector como productor del texto, en concreto, la respuesta de Michel Foucault al citado ensayo "La muerte del autor" de Roland Barthes, ya que permite comprender las sutiles fronteras entre comunidad y autoridad en el contexto de la antología, y, así, repensar el doble estatuto del antólogo al que se viene aludiendo.

Foucault presta atención al autor no como el personaje atendido por la crítica positivista y rechazado por Barthes, sino como una "función autor" definida por la puesta en marcha de complejas operaciones de atribución (Foucault, autor 42). Para Foucault, el nombre propio que identifica un corpus artístico no supone un mero indicador de la procedencia del texto, sino que tiene una incidencia en el discurso que no es obviada por el lector al interpretarlo. En consecuencia, es necesario "localizar, como lugar vacío -indiferente y apremiante a la vez- los sitios en donde [el autor] ejerce su función" (Foucault, autor 33). El nombre, la relación de apropiación con la obra, y su posición en el libro de la mano de los espacios editoriales que, como los prefacios, están destinados a proyectar su identidad, constituirán los principales focos donde esta "función autor" se manifiesta".

Como ha quedado señalado, existen en la antología poética espacios en los que, siguiendo las ideas de Foucault, se ejerce una "función autor". Los paratextos que la definen pueden ser considerados "piezas de autor" (Kamuf), que dotan de autoridad al discurso y que singularizan el nombre propio que ocupa la cubierta distinguiéndolo del de un mero recopilador. Así, existe en la antología un yo autorial que se refleja en las relaciones de apropiación con los textos reordenados y fragmentados con respecto a los libros originales (Ruiz Casanova 38), en el prólogo en el que se justifican las inclusiones y los olvidos, o en el uso de determinadas citas que constituyen, siguiendo

que no están distribuidas universalmente" (268), por lo que su condición de "superlector" estaría condicionada por su pertenencia a los grupos privilegiados por las relaciones de poder y a la distribución y la transformación del "capital simbólico" en el campo literario.

Tal y como han documentado Aina Pérez Fontdevila y Meri Torras Francés (18), la perspectiva adoptada por Foucault en este ensayo influirá en la posterior recuperación de la figura autorial en la teoría literaria reciente, que ha tratado de abordar la autoría al margen tanto de la perspectiva positivista rechazada por Barthes como de la neutralidad que este atribuía a la escritura. 
la noción de Gérard Genette, "umbrales", esto es, zonas de paso entre el adentro y el afuera del texto que determinan su sentido (Genette 7-8). En su conjunto, estos elementos contribuyen a que la firma sea identificada a través del "reconocimiento de los modelos propuestos" (Ruiz Casanova 42).

Desde estos presupuestos teóricos, es necesario detenerse en un caso concreto que dé debida cuenta del estrecho vínculo entre las prácticas de lectura del antólogo y los procesos de atribución del discurso ligados a la autoría. Para este fin, pocos ejemplos revisten en la literatura española contemporánea tanto interés como el de Josep Maria Castellet, responsable de dos de las antologías que más atención han recibido por parte de la crítica especializada: Veinte años de poesía española (1960) y Nueve novísimos poetas españoles (1970). Aunque se han dedicado notables trabajos a abordar el proceso de elaboración de ambos textos (Riera 176-208; Prieto de Paula 86-92; Lanz 392-457; Benéitez Andrés), y a su influencia en la consolidación de determinados nombres en el canon posterior (Díez de Revenga; García, "Historiografía" 54-60; Penalva), no ha existido un interés por la evolución de la identidad autorial del antólogo entre uno y otro libro, una cuestión a la que el marco teórico trazado previamente permite prestar atención.

A lo largo de los diez años que median entre la publicación de ambas antologías, el reconocimiento de Josep Maria Castellet como crítico y lector privilegiado de su tiempo queda confirmado en las numerosas reediciones de Veinte años (entre las que se cuenta una versión ampliada bajo el título $U n$ cuarto de siglo de poesía española en 1965), un éxito en la distribución de sus selecciones que es revelador de la temprana huella de su propuesta en el mercado editorial. Así, si ensayos tan influyentes en el panorama crítico español de los años cincuenta como Notas sobre literatura española contemporánea (1955) o La hora del lector (1957) resultan determinantes para construir la legitimidad del antólogo como "lector informado", la notoriedad adquirida a raíz de la aparición de Veinte años permitirá que, cuando se edite Nueve novísimos poetas españoles (1970), el nombre Castellet sea, para gran parte del público, el de un autor de antologías.

De acuerdo con este planteamiento, para Túa Blesa, la polémica derivada de Nueve novísimos, fruto de la adopción, en el prólogo y en la muestra, de unos principios que contradecían la defensa, en la antología anterior, de la poética realista ${ }^{6}$ como tendencia dominante en la literatura española entre 
1939 y 1959, no se debía tanto al distanciamiento temático y estético entre ambas selecciones, como a que la segunda "venía a integrase en una cadena formada por otros textos a los que unificaba la firma 'José María Castellet' $\mathrm{y}$, entre ellos, de manera muy especial por razón del género, anteriores trabajos antológicos" (Blesa 107). Blesa acierta así a vislumbrar que ambas antologías constituyen un corpus textual atribuido a un autor conocido, lo que, necesariamente, apunta a las características de la "función-autor" a la luz del ensayo de Foucault. El nombre de Josep Maria Castellet dota, pues, de coherencia a dos conjuntos eclécticos y genera en quien lee unas expectativas que, sin embargo, se romperían con la inclusión en Nueve novísimos de planteamientos que "disienten radicalmente" (Castellet, Nueve 11) con los defendidos en la antología de 1960.

Este cambio en la "poética" adoptada por el antólogo pondrá de manifiesto la existencia de una marcada proyección autorial. En consecuencia, en la antología se produce un estrecho vínculo entre la gestación de una lectura autorizada, en el marco de la "comunidad interpretativa", y la atribución de textos heterogéneos a un autor concreto de la mano de un estilo unificado por la firma. En este sentido, a pesar de que se ha defendido la intervención de intelectuales del círculo de Castellet en la elección de los poemas y poetas propuestos en sendas antologías (Riera 179; Prieto de Paula 86), estas reflejan el yo de un "lector informado" que deviene productor del texto a través del prólogo, de la fragmentación y la posterior ordenación de poemas y, en especial, de los ya citados paratextos, ya que, debido a su naturaleza "transaccional" (Genette 8), y a su repetido emplazamiento en el objeto libro, evidencian la relación de apropiación establecida con las obras ajenas.

Desde esta óptica, no se debe obviar que los planteamientos teóricos que subyacen a la preparación de Veinte años de poesía española habían sido previamente vertidos por el propio antólogo en La hora del lector (1957), un ensayo que adelanta en gran medida algunas de las teorías de la respuesta

\footnotetext{
"realismo crítico" de los años cincuenta, encarnado en una serie de poetas jóvenes a quien la antología pretendía promocionar, supondría la cumbre de una progresiva evolución hacia una literatura comprometida que se habría comenzado a producir desde el final de la Guerra Civil española en 1939 (Castellet, Veinte 57-58; Riera 200). Sin embargo, los presupuestos estéticos manejados para la confección de Nueve novísimos, que insistían en la ruptura con respecto a la poética socialrealista inmediatamente anterior (Lanz 399), suponían un cambio tan radical en la concepción de la poesía española del tardofranquismo manejada por el crítico que despertaría un interés singular por la nueva selección (Prieto de Paula 86-91).
} 




Fig. 1

del lector más influyentes del siglo xx (Albaladejo y Gómez Alonso 68). Castellet defiende en este trabajo que la irrupción de la narrativa moderna habría motivado, a través de sus diversas técnicas, la "idea de la lectura como creación" (Castellet, La hora 47), de modo que "el lector participa con el escritor en la creación de la obra literaria" (Castellet, La hora 48). Para el crítico, esta "doble creación" (Castellet, La hora 53) por parte de autores y lectores se apreciaría también en la poesía, por lo que, en cierto modo, la antología supondría uno de los espacios en los que esta autoría múltiple se pone de manifiesto de la mano de una cierta "malinterpretación" que, siguiendo la perspectiva posterior de Harold Bloom, modificaría el sentido de las obras escogidas y determinaría la condición autorial del antólogo.

En este sentido, queda abierto el cauce para recuperación del autor a través de los paratextos que acompañan a la selección. Así, una de las claves de la evolución de la identidad autorial de Josep Maria Castellet como antólogo entre Veinte años y Nueve novísimos reside en la importancia que la reproducción de su retrato cobra en la segunda muestra, ya que se convertirá en uno de los espacios paratextuales de mayor importancia para la cohesión a través de un "yo integrador de las conciencias singulares" (Lanz 388) que componen el conjunto. Desde los estudios autoriales francófonos, continuadores de la estela del Foucault de "¿Qué es un autor?”, el aparato iconográfico no supone un mero elemento decorativo, sino que constituye una pieza clave en la delimitación del sentido del texto (Dewez y Martens; Martens y Reverseau). Si la fotografía (fig. 1) de Castellet que ocupa el centro de la contracubierta de Nueve novísimos se compara con el retrato del antólogo que acompañaba

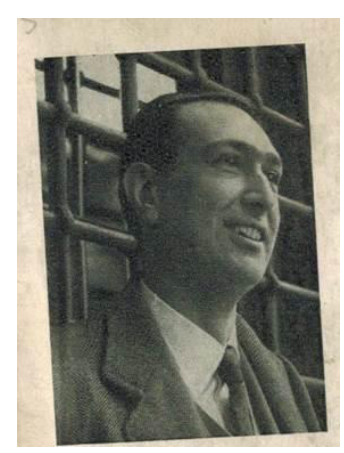

Fig. 2 La hora del lector (1957) (fig. 2), se apreciará que, con la antología de 1970, habrá un cambio notable en la autopresentación: mientras que los libros previos proyectan una imagen de Castellet marcada por la formalidad, en la selección de 1970 no solo ha sido modificada la apariencia del crítico (que muestra una imagen desenfadada con el pelo más largo), sino que la perspectiva de la fotografía, tomada a través de un espejo, así como la presencia del icono pacifista adherido al mismo, enmarca el significado de los 
poemas recogidos. Tanto el retrato, como la nota que lo acompaña ("José $\mathrm{M}^{\mathrm{a}}$ Castellet, nacido en Barcelona en 1926, viene encarnando, como crítico y como antólogo, las posiciones más polémicas en el seno de la literatura española, desde el inicio de los años 50"), promueven la popularización de una imagen del antólogo como polemista que dista mucho de la representación del crítico reconocido adoptada en obras previas.

Desde esta perspectiva, la fotografía de Castellet constituye en Nueve novísimos una de las claves de la participación del antólogo en el "régimen mediático" en el que Nathalie Heinich (34-37) inserta la circulación de los bienes culturales en la época contemporánea, ya que, como advierte Méndez Rubio (24-25), la publicidad, uno de los rasgos axiales de la sociedad posmoderna, cobra una gran importancia en las antologías publicadas en la España de los años setenta. Con Nueve novísimos, se produce "la eclosión publicitaria generacional" (Talens 72) que resulta fundamental para la consolidación de un canon de la poesía española de los años setenta. Un fenómeno que no hubiera cobrado las dimensiones sugeridas por Talens sin la acentuación de los rasgos asociados a la "función autor" de la mano de la proyección de una imagen del antólogo como autor a través de herramientas, como la fotografía, ligadas a la visibilidad del escritor. La importancia de la presentación del autor en Nueve novísimos queda probada por la repetida reproducción de una imagen similar hasta el final de la trayectoria de Castellet. En este sentido, no parece casual que, en varias reediciones recientes de la misma antología se opte por una fotografía del antólogo para ilustrar la cubierta (fig. 3 y fig. 4), un fenómeno poco frecuente en libros de este tipo, donde la diversidad de nombres incluidos parece limitar la referencia al seleccionador a espacios editoriales como el prólogo o la firma en la cubierta.

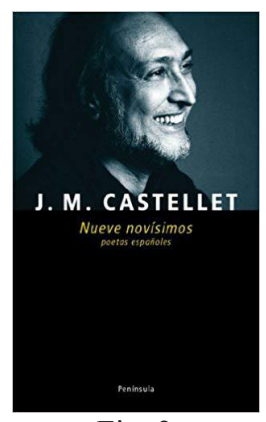

Fig. 3

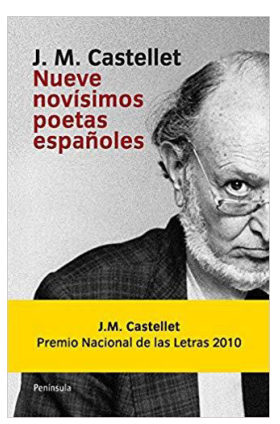

Fig. 4

El análisis de estos documentos confirma que, entre la publicación de Veinte años de poesía española y la de Nueve novísimos poetas españoles, se afianza la "imagen de autor" (Maingueneau) de Josep Maria Castellet como antólogo. Si ensayos previos como La hora del lector se centraban en legitimar su papel como "lector informado", ahora la voluntad programática de la antología determina una cercanía más estrecha con respecto al texto. 
Desde esta perspectiva, urge ahora preguntarse por las implicaciones que esta concepción del antólogo como autor tiene en la construcción de una determinada imagen de los seleccionados/as, una cuestión que resulta especialmente pertinente a la hora de repensar el complejo estatuto de las poetas que, como excepciones de su sexo, son incluidas en las antologías de corte programático. Por este motivo, asumida su condición de "escritor de segundo grado" (Guillén 413), será necesario recorrer a continuación algunas de las aportaciones feministas al debate en torno la lectura con el fin de valorar la apropiación que el antólogo lleva a cabo de los textos escritos por mujeres, que pasarán a formar parte de un proyecto de legitimación de una firma y de la activación en el libro de la "función autor".

\section{LA LECTURA DESDE LA CRÍTICA LITERARIA FEMINISTA: EL ANTÓLOGO COMO LECTOR}

A raíz de la gran influencia en los Estados Unidos de los trabajos de Roland Barthes, la crítica literaria feminista comenzó a cuestionar las teorías de la lectura surgidas con el estructuralismo por obviar las marcas de raza, clase y género que interfieren en esta actividad (Schweickart 118). Con el fin de acabar con la extendida imagen de un lector neutro, se asumió que la manera en que determinadas interpretaciones -consideradas como legítimas en contextos fuertemente institucionalizados como el académico- habían determinado la exclusión de las obras escritas por mujeres debía ser uno de los ejes centrales de todo análisis en torno a la interpretación. De este modo, en la temprana fecha de 1969, Kate Millett introducía en su ensayo Política sexual la perspectiva feminista en los debates en torno a la lectura al defender la necesidad de llevar a cabo prácticas interpretativas en desajuste con los significados dominantes, con lo que se rechazaba a un tiempo la primacía del autor a la hora de dotar de sentido al texto y el papel de la crítica hegemónica en la delimitación de sentidos válidos. Bajo esta premisa, y a partir de la revisión de fragmentos de obras de D.H. Lawrence, Henri Miller, Norman Mailer y Jean Genet, Millett tenía como objetivo estudiar cómo se representaba la dominación entre los sexos en la literatura y demostrar que toda lectura debía tratar de "captar los reflejos bien definidos que la literatura ofrece de esa vida que describe, interpreta e incluso deforma" (Millett 28).

En este ensayo quedaba ya expresado que toda crítica feminista en torno a la lectura debía comenzar revisando las bases que sustentan el canon 
androcéntrico, para así poner en cuestión la autoridad de la interpretación hegemónica y proponer alternativas feministas (Schweickart 125). Elaine Showalter expresaba objetivos similares al dirigir en 1971 su atención a las repercusiones que un currículo escolar formado únicamente por obras escritas por hombres tenía en la asimilación por parte de las estudiantes del punto de vista masculino y cerrado que considera la óptica femenina como parcial y marcada (Showalter, Women 855). Para Showalter, la universidad funcionaría como una de las "comunidades interpretativas" definidas por Stanley Fish, donde se enseña a sus miembros a reproducir unas prácticas concretas, y en las que las lectoras son instruidas para aceptar el prisma masculino como normal y legítimo, situación ante la que no pueden sino adoptar una postura a la que Judith Fetterley llamó "resistente" (Fetterley viii), es decir, establecer un nuevo vínculo con los textos a través de una lectura en disenso con los poderes que han dictado su significado. Se trataba de una serie de propuestas destinadas, en palabras de Lola Luna, a leer "como una mujer la imagen de la mujer", a reparar en cómo lo femenino "funciona como sistema de exclusión del discurso y que, por tanto, inscribir o mostrar la diferencia siempre tiene connotaciones ideológicas para un lector masculino" (Luna 14).

A partir de estas premisas iniciales, la crítica feminista desplazó su interés desde el estudio de la producción masculina hacia la investigación de las obras de autoría femenina, denominada "ginocrítica" por Elaine Showalter (La crítica 82), lo que supuso resituar el centro de interés en las "estrategias críticas androcéntricas que desplazaban los textos de las mujeres a los márgenes del canon" (Schweickart 131). En consecuencia, las investigadoras confrontaron las teorías de lectura para encontrar en ellas las claves que determinaban no solo la ausencia de las escritoras de las antologías y las historias de la literatura, sino también la interpretación que se les había dado a sus novelas y poemas cuando estos eran excepcionalmente reconocidos. Así, el clásico ensayo de Sandra Gilbert y Susan Gubar, The Madwoman in the Attic (1979), trasladaba las inquietudes expuestas por Kate Millett una década antes al estudio de un grupo de escritoras aceptadas en la tradición anglófona con el propósito de demostrar que las interpretaciones hegemónicas (y comúnmente aceptadas) de sus obras habían pasado por alto la impronta de la cuestión de género. Para las profesoras, las novelas de Jane Austen o Charlotte y Emily Brönte, y la poesía de Emily Dickinson abundaban en imágenes como las de la casa o la prisión que revelaban una inquietud ligada a la condición femenina de las autoras a la que no se le había otorgado la necesaria atención, lo que demostraba hasta qué punto la existencia de un lector neutro había de ser cuestionada (Gilbert y Gubar 11). 
Desde esta óptica, no resulta extraño que planteamientos en torno a la actividad interpretativa como los de Stanley Fish fueran bien acogidos tanto en el seno de la crítica literaria feminista -ya que su propuesta permitía identificar en la lectura patrones que son determinantes en la exclusión y en el sesgo con el que la crítica tradicional se ha acercado a las obras escritas por mujeres (Schweickart 141)-, como en los debates que, desde la deconstrucción, se produjeron en torno a esta práctica en la década de los ochenta. En este contexto, retomando la propuesta de Fish sobre la existencia de "lectores informados" y haciéndose eco de los planteamientos feministas de las décadas previas, Jonathan Culler planteaba en On Deconstruction (1982) la problemática del papel desempeñado por la experiencia individual en la asunción de determinados métodos interpretativos ligados a una "comunidad interpretativa" (Culler 41). La consideración de Fish sobre el hecho de que ciertas creencias no podrían ser obviadas por los "lectores informados" suponía para Culler un excelente punto de partida para reflexionar sobre qué significa "leer como mujer", una cuestión que enraizaba en el cambio de paradigma en los estudios literarios propiciado por la crítica feminista. Para Culler, "leer como una mujer no es necesariamente lo que sucede cuando una mujer lee" (Culler 48), ya que, como habían demostrado trabajos como los arriba citados (Millett; Showalter), las mujeres pueden y, de hecho, han leído como hombres de acuerdo con la formación académica recibida. En consecuencia, el sintagma "leer como una mujer" haría alusión no a una experiencia previa y compartida por todos los sujetos del mismo sexo, sino a la representación en la lectura de una identidad construida que se ha hecho coincidir con la identidad de la mujer (Culler 61).

Si bien las principales objeciones al trabajo de Culler se apoyaron en la reconsideración de la experiencia propia de las mujeres que la perspectiva deconstructivista corría el riesgo de pasar por alto (Modleski; Scholes), el ensayo "Reading like a Feminist" (1989) de Diana Fuss alertaría de los riesgos de ambos extremos. Contra la tendencia generalizada en investigaciones previas a la utilización del binomio hombre/mujer, Fuss insiste en la "posición-sujeto" que ocupa cada lector/a (Fuss 136). Esta noción, introducida por Michel Foucault en La arqueología del saber (1969) y recuperada en los estudios sobre lo subalterno de Gayatri Spivak, es, para Fuss, un concepto clave a la hora de enfrentarse a la problemática relación entre lectura y género, ya que permite articular importantes preguntas en torno a la gestación del significado de los discursos pasadas por alto con anterioridad. Si Foucault define el "juego de posiciones posibles para un sujeto" (Foucault, La arqueología 
183) como un elemento central en la descripción de los enunciados y, por tanto, en la definición de la subjetividad, para Spivak, es "inevitable" (Spivak 229) hablar o escribir desde una posición sujeto. Esta metáfora permitiría así valorar dónde se sitúa cada individuo con respecto al texto, y tendría un énfasis antiesencialista que, sin embargo, no ocultaría la naturaleza sexuada de las dinámicas de comprensión de la obra.

Para Fuss, tan necesario es prestar atención a las posiciones que puede ocupar un sujeto lector como a la manera en que estas se construyen dentro y fuera del discurso (Fuss 140), ya que, en el proceso de lectura, la posición ocupada con anterioridad por el individuo se entrelaza con las propuestas de posición lanzadas por el propio texto (Fuss 141). Esta inestabilidad, que transciende la división entre una lectura masculina y hegemónica y una lectura en clave de mujer, contribuye a vislumbrar la naturaleza histórica y variable de esta práctica (Fuss 144), y encierra un enorme potencial tanto para comprender la relación de las lectoras con las obras escritas por hombres, como para abordar cómo las interpretaciones de la literatura firmada por mujeres han fluctuado a lo largo de la historia y han estado en gran medida determinadas por las "posiciones-sujeto" ocupadas por ellas mismas y por los "lectores informados" en el tejido social.

A partir de estos planteamientos, la antología supone un espacio de gran interés para estudiar cómo la lectura está marcada por una negociación entre "posiciones-sujeto", porque, si bien las escritoras pueden estar representadas en la muestra, la firma del antólogo condicionará en gran medida el sentido que adquieran tanto los textos escogidos como el conjunto de sus obras, de modo que la propuesta interpretativa implícita en el propio poema estará atravesada por la autoridad que lo reescribe. Asimismo, la "posición-sujeto" que ocupa el antólogo está moldeada por la "comunidad interpretativa" en la que su labor se inserta, y desde la que se proyecta como autor del nuevo conjunto, por lo que, siguiendo las aportaciones de Diana Fuss, algunas de las preguntas que habrán de plantearse serán las siguientes: 1) ¿Existe una renuncia por parte del antólogo a ocupar la "posición-sujeto" que determinados textos escritos por mujeres proponen? y 2) ¿cómo se relaciona la propuesta de lectura y la autorialidad que el antólogo adquiere a través de la antología con unas poéticas con una clara impronta de género?

Para responder a estas cuestiones, será preciso recuperar los presupuestos previos en torno a la construcción de una identidad autorial del antólogo con el fin de comprender la relación establecida entre la "posición-sujeto" que ocupa como lector y autor del conjunto y la interpretación de una serie 
de obras cuya marca de género parece proponer una lectura "resistente" (Fetterley viii) con respecto a los planteamientos interpretativos hegemónicos. En este sentido, resulta especialmente relevante prestar atención al lugar que determinados poemas de autoría femenina ocupan en Veinte años de poesía española $(1960)^{7}$, primera de las muestras programáticas preparadas por Castellet y selección fundamental para el establecimiento de la corriente poética realista como canónica en las historias de la literatura posteriores (García, "Historiografía" 54). A pesar de que el sesgo que subyace a la "interpretación histórica" (Castellet, Veinte 13) de la poesía española de las décadas de los años cuarenta y cincuenta formulada por Castellet ha sido conectado con la voluntad programática del conjunto (Riera 208), aún no se ha prestado la suficiente atención a la repercusión que su lectura firmada ha tenido al neutralizar las singularidades de las tres únicas poetas incluidas en la selección: Ángela Figuera Aymerich, Gloria Fuertes y María Beneyto.

En un lúcido ejercicio de comprensión de la historia de la literatura de la segunda mitad del siglo xx, Miguel Casado describió con exactitud los procedimientos que resultan determinantes en la eliminación de los matices que caracterizan a las voces que, aun disintiendo de este tipo de selecciones, son incluidas para apoyar la hipótesis defendida por críticos/as y antólogos/ as. Para Casado, a una fase delimitadora, en la que se señalan los nombres que conforman la generación, le sucede una maniobra simplificadora en la que "se propone no ya la selección de nombres, sino el diseño de la tendencia estética dominante en el grupo generacional" (Casado 33). Como consecuencia, si bien algunos/as poetas son incluidos/as en antologías de referencia, "sus rasgos más característicos se excluyen, no forman parte del retrato modelo del grupo" (Casado 33). Este mecanismo de reducción de un mapa poético complejo es claramente apreciable en la inclusión por parte de Castellet de ciertos poemas escritos por mujeres en la década de los cincuenta, y ha de ser estudiado en relación con la "posición de lectura" ocupada por el antólogo,

\footnotetext{
Si bien es posible llevar a cabo una lectura de Nueve novísimos desde este punto de vista, para el desarrollo de este trabajo concreto, Veinte años encierra un mayor interés tanto por el mayor número de autoras incluidas como por la más extensa trayectoria con la que Ángela Figuera Aymerich, Gloria Fuertes y María Beneyto contaban en el momento en que aparece la antología de 1960. El caso de Ana María Moix (la única autora incluida en Nueve novísimos) difiere en gran medida del de las anteriores por haber publicado su primer libro de poemas, Baladas del dulce Jim (1969), tan solo un año antes de la aparición de esta antología.
} 
y como resultado de la activación en la antología de la "función autor" que resulta determinante para la cohesión del conjunto.

Contra la tendencia generalizada en otras antologías de esta etapa a subrayar la naturaleza diferencial de las obras escritas por mujeres (incluso cinco años después de la publicación de Veinte años, Luis López Anglada separaba en su Panorama poético español a las escritoras incluidas en el apartado "La mujer en la poesía contemporánea"), en Veinte años, la voluntad programática exigía llevar a cabo la actividad inversa: neutralizar aquellos rasgos que se apartasen de la poética defendida en el conjunto con el fin de dotar de coherencia a la propuesta. En este caso, se trataba de destacar aquellos poemas en los cuales existiera una clara inclinación al compromiso social que probase la preeminencia en la España del período comprendido entre 1939 y 1959 de una tendencia poética realista. En consecuencia, la lectura que subyace a la muestra recogida de Ángela Figuera Aymerich, Gloria Fuertes y María Beneyto no es sino el reflejo de determinadas estrategias destinadas a legitimar a un grupo poético concreto a través del papel de "lector informado" que representa el antólogo.

En el extenso prólogo a Veinte años, uno de los espacios por excelencia donde se activa la "función autor", Castellet describe la línea de fuerza de la propuesta estética que está en la base de su lectura y de la recreación de textos preexistentes: "El tema de esos poetas es el hombre histórico que pertenece a un mundo en transformación y al que, tenga o no tenga conciencia de ello, las circunstancias urgen dramáticamente, obligándole a comprometerse con su época" (Castellet, Veinte 102). En la cita, Castellet admite la posibilidad de que los incluidos/as estén al margen del programa estético defendido a través de la afirmación "tenga o no tenga conciencia de ello", una tesis que contribuye a legitimar su interpretación de los textos escogidos por encima de la de su propio autor/a. Esta definición de la literatura de su tiempo, escasa en matices, muestra al antólogo como "lector informado" y, por tanto, resulta problemática desde la perspectiva de la lectura feminista. Como ya han demostrado diversos trabajos sobre las poetas de posguerra (Arkinstall; Payeras Grau, Espejos 37), si bien es cierto que las escritoras seleccionadas se acercan en ciertos momentos de su trayectoria a la poesía social, introducen rasgos específicamente vinculados con su condición de mujeres bajo el franquismo que serían pasados por alto al ser leídos (y reescritos) desde una óptica falsamente universalista como la presentada en el fragmento previo. En consecuencia, merece la pena ofrecer aquí un sucinto análisis de la interpretación ofrecida por Castellet de las tres poetas incluidas en la antología para comprobar hasta qué punto la "posición-sujeto" propuesta 
en sus textos es rechazada cuando los objetivos del antólogo precisan de la homogeneización de poéticas divergentes.

El primer poema de autoría femenina reproducido en Veinte años es "Antonio Machado" de Ángela Figuera Aymerich ${ }^{8}$. El título establece un estrecha relación con uno de los paratextos de la antología, la dedicatoria -"a la memoria de Antonio Machado, en el XX aniversario de su muerte"-, que convertía al poeta sevillano en símbolo del realismo histórico defendido en la muestra (Riera 193). Castellet escoge un momento concreto de la producción de Ángela Figuera Aymerich -correspondiente al libro Soria pura (1949)marcado por la influencia de Machado (Payeras Grau, El linaje 25) para reforzar la poética defendida en el nuevo conjunto. Algo similar ocurre con "Veinte años", extraído de Belleza cruel (1958), que tiende un puente hacia el título de la antología. Estas elecciones confirman la necesidad de leer los paratextos como "piezas de autor" (Kamuf) del antólogo que condicionan no solo el sentido de los fragmentos de obra ajena escogidos, sino también la "imagen de autora" (Maingueneau) de las seleccionadas. Desde esta perspectiva, la inclusión de "La cárcel" (Castellet, Veinte 260-261), en el que se da voz a un preso, pone de manifiesto la concepción del compromiso defendida por Castellet, ya que, en gran parte de los textos de El grito inútil (1952) -volumen en el que aparece originalmente el poema-, el papel de las mujeres en la resistencia al franquismo ("El grito inútil", "Rebelión") y su condición como víctimas de la precariedad ("Mujeres de mercado", "Culpa", "Pobre", "Éxodo", "Estación", "Y ahora el llanto") desempeña un papel central que, en la antología, es pasado por alto. Al contrario que una gran parte de la crítica de su tiempo, que opta por subrayar la vinculación de la trayectoria de Ángela Figuera Aymerich con temáticas como la de la maternidad (Luis 327; Bosch), Castellet destaca la faceta de su obra menos marcada por el género, procedimiento que le permite situarla al lado de los escritores que pretende consolidar.

Los poemas que Castellet ofrece de Gloria Fuertes, "El alba se ha puesto fría" (Castellet, Veinte 286), incluido originalmente en el libro Aconsejo beber hilo (1954), y "Ante un muerto en su cama" (350-351), que había aparecido en el número 61 (1957) de la revista Poesía española, expresan un compromiso del que vuelve a estar ausente la perspectiva de género que también ha sido considerada una de las señas de identidad de la obra de la

He abordado previamente la relación de Ángela Figuera Aymerich con esta antología de Castellet (Fernández Menéndez). 
poeta madrileña (Sherno 372; Logan Cappuccio 90; Payeras Grau, Espejos 100; Vila-Belda). Como ocurría en el caso de Ángela Figuera Aymerich, la fragmentación exigida en la preparación de la antología conlleva a rechazar la "posición de lectura" propuesta por el poemario Aconsejo beber hilo (libro que el antólogo parece tomar como referencia para elaborar la muestra). En su contexto original, "El alba se ha puesto fría" establece una estrecha relación con la "posición de lectura" lanzada por el resto de poemas del libro (Fuertes), cuya problematización en torno a la tensión entre escritura y mujeres ("No dejan escribir", "Voy haciendo versos por la calle"), la identidad de género ("No sé", "El del pez", "Cuarto de soltera"), la locura ("Llantos nocturnos") o la prostitución ("Paliduchas") permite comprender el sórdido ambiente de posguerra desplegado en el texto elegido por Castellet en la intersección con temáticas que plantean una mirada alternativa al "realismo histórico" propuesto por el antólogo. Sin embargo, la disposición de los paratextos y de los textos en la antología (en la que, de un total de 139 poemas, solo seis son de autoría femenina) contribuye a una concepción del compromiso supeditada a la "función autor" del antólogo y minimiza el potencial subversivo de la propuesta de Gloria Fuertes.

Un matiz diferente ofrece el único poema de María Beneyto recogido por Castellet, ya que "Nocturno de la cárcel de mujeres" introduce, desde el título, a las mujeres como sujetos, un rasgo que promoverá una lectura que pondría en cuestión los planteamientos universalistas que subyacen al "hombre histórico" mencionado por Castellet en el prólogo. Incluido como una de las muestras representativas del año 1956, fecha de publicación del libro original, Poemas de la ciudad, es el único poema escogido en la muestra que se refiere explícitamente a la condición de la mujer. Así, si bien resulta obvia la aproximación de este texto a la temática del compromiso defendida por el antólogo de la mano de la focalización en las mujeres como víctimas de la cárcel franquista, la inclusión de un solo ejemplo de la escritora en Veinte años no solo fomenta una interpretación de la perspectiva de género como excepción al marco universalista, sino que, además, supone omitir rasgos esenciales de la trayectoria de María Beneyto que pondrían en cuestión la legitimidad de la apuesta de Castellet y, por tanto, su autoridad como "lector informado".

Es preciso señalar que la propia María Beneyto destacará al final de su trayectoria la vinculación de Poemas de la ciudad (frente a los anteriores Canción olvidada, Eva en el tiempo y Criatura múltiple) con la poesía social: "Era una poesía con menos yo, más solidaria, más humana, más 'social' si quiere llamársela así, aunque yo la quise, hasta donde pude controlarla, más 
que otra cosa, testimonial" (Beneyto 112). De este modo, como lectora de su obra, Beneyto no niega la filiación de este libro con la "interpretación histórica" (Castellet, Veinte 13) defendida por Castellet. Sin embargo, al preparar la selección de poemas para la misma antología en la que se recogen estas palabras, no parece tampoco casual que la poeta no incluya ningún texto de Poemas de la ciudad, ni que apenas estén representados los poemarios que ella misma considera próximos a esta tendencia (Tierra viva, Vida anterior y, en menor medida, El agua que rodea la isla y Biografía del silencio). Nos encontramos, por tanto, ante dos "posiciones-sujeto" divergentes sobre la lectura de una obra literaria concreta, lo que resulta, a su vez, revelador de dos identidades autoriales en conflicto: la desplegada por el antólogo que prepara una selección canónica de acuerdo con una voluntad programática, y la de la poeta que autoselecciona sus obras al final de su trayectoria con el fin de construir una imagen de sí ante el público lector. En el ejemplo citado, ambas lecturas, la promovida por Castellet y la que, más tarde, llevará a cabo la propia María Beneyto, están atravesadas por la necesidad de proyectar una determinada "imagen de autor" (Maingueneau) que pone en evidencia la estrecha relación de las prácticas de lectura y escritura en la construcción de la historia de la literatura.

El ejemplo de las tres autoras incluidas en Veinte años demuestra hasta qué punto la reproducción de los textos escritos por mujeres en antologías generalistas debe ser analizada prestando atención al doble papel del antólogo como autor y lector del conjunto. Por un lado, se trata de reparar en la naturaleza "múltiple, cambiante y cambiable" (Fuss 144) de textos que motivan "posiciones-sujeto" que están atravesadas por una clara perspectiva de género. Por otro, no es posible obviar la condición del antólogo como autor de un conjunto nuevo, ya que podría llegar a cuestionar el significado propuesto por las propias poetas en textos metapoéticos o en el marco de sus libros de creación.

\section{CONCLUSIONES: LAS DOS CARAS DE JANO}

A partir de algunas de las aportaciones teóricas más destacadas en torno a la agencia del lector, en este trabajo se ha propuesto un marco de estudio para las antologías poéticas que preste atención a la complejidad de los procesos de interpretación y de canonización de las obras literarias, un planteamiento que ya había sido expuesto en los estudios literarios españoles por parte de Claudio Guillén y José Francisco Ruiz Casanova. Repensar la actividad del 
antólogo como una lectura firmada permite, por un lado, valorar el peso que ciertas prácticas interpretativas han tenido en el devenir de las obras escritas por mujeres y, por otro, dotar al conjunto de una clara autoría, de una firma que atraviesa, a su vez, nuestra lectura y consideración de la poesía de autoría femenina.

Como el dios Jano, el antólogo parece ser una figura bifronte que aúna en su tarea dos actividades complementarias (lectura y la escritura), y que se localiza entre la construcción de una imagen de los y las poetas escogidos y una autorrepresentación como agente legitimado para dilucidar el valor de los textos literarios. Esta ambivalencia no hace sino subrayar la naturaleza transaccional de toda lectura, determinada, como bien ha comprendido Diana Fuss, por la "posición-sujeto" ocupada por los distintos individuos que se enfrentan a un texto y participan de la inestabilidad de sus significados. Esta hipótesis invita, pues, a un nuevo análisis en profundidad de las antologías que han gozado de una amplia circulación en el campo poético español contemporáneo, $\mathrm{y}$, especialmente, a un replanteamiento de las complejas relaciones que las escritoras establecen con estos volúmenes que, en algunos casos, han incluido muestras de una producción que se aparta de los gustos dominantes.

\section{BIBLIOGRAFÍA}

Albaladejo, Tomás y Juan Carlos Gómez Alonso. "La lectura como actividad y La hora del lector: Josep Maria Castellet”. De sombras y de sueños. Homenaje a J. M. Castellet. Ed. Eduardo A. Salas Romo. Barcelona: Península, 2001. 68-80.

Alonso Valero, Encarna. Machismo y vanguardia: escritoras y artistas en la España de preguerra. Madrid: Devenir, 2016.

Arkinstall, Christine. "Rhetorics of Maternity and War in Ángela Figuera's Poetic Work". Revista Canadiense de Estudios Hispánicos 21.3 (1997): 457-478.

Barthes, Roland. El susurro del lenguaje. Más allá de la palabra y de la escritura. Barcelona: Paidós, 1994.

Crítica y verdad. Buenos Aires: Siglo xxi, 1972.

Bayo, Emili. La poesía española en sus antologías (1939-1980). Lleida: Universitat de Lleida, 1994.

Benéitez Andrés, Rosa. “AAlgo nuevo con los novísimos?”. Bulletin of Hispanic Studies 92.5 (2015): 551-566.

Beneyto, María. "Poética". En voz alta. Las poetas de las generaciones de los 50 y los 70. Antología. Ed. Sharon Keefe Ugalde. Madrid: Hiperión, 2007. 111-114.

Bloom, Harold. A Map of Misreading. New York: Oxford University Press, 1975. 

1997.

The Anxiety of Influence. A Theory of Poetry. New York: Oxford University Press,

Blesa, Túa. "La destrucción de los viejos mitos". De sombras y de sueños. Homenaje a J. M. Castellet. Ed. Eduardo A. Salas Romo. Barcelona: Península, 2001. 105-124.

Bosch, Rafael. "La poesía de Ángela Figuera y el tema de la maternidad”. Ínsula 186 (1962): 5-6. Bourdieu, Pierre. La distinción. Criterio y bases sociales del gusto. Barcelona: Taurus, 2015. Casado, Miguel. Los artículos de la polémica y otros textos sobre poesía. Madrid: Biblioteca Nueva, 2005.

Castellet, José María. Nueve novísimos poetas españoles. Barcelona: Seix Barral, 1970. Veinte años de poesía española. Barcelona: Seix Barral, 1960. La hora del lector. Barcelona: Seix Barral, 1957.

Champeau, Geneviève y Nadine Ly. Le phénomène anthologique dans le monde ibérique contemporain. Bordeaux: Presses Universitaires de Bordeaux, 2000.

Culler, Jonathan. Sobre la deconstrucción. Teoría y crítica después del estructuralismo. Madrid: Cátedra, 1998.

Dewez, Nausicaa y David Martens. "Iconographies de l'écrivain. Du corps de l'auteur au corpus de l'œuvre". Interférences littéraires 2 (2009): 11-23.

Díez de Revenga, Francisco Javier. "El 27 y Un cuarto de siglo de poesía española (canon e historiografía literaria del siglo xx). De sombras y de sueños. Homenaje a J. M. Castellet. Ed. Eduardo A. Salas Romo. Barcelona: Península, 2001. 173-185.

Fernández Menéndez, Raquel. "Autoría femenina y compromiso en la posguerra española: para un estudio de las antologías". Formas de la rebeldia en la literatura hispánica. Eds. Miguel Ángel Gómez Soriano, Ignacio Ballester Pardo y Ferrán Riesgo. Sevilla: Renacimiento, 2020. 226-239.

Fetterley, Judith. The Resisting Reader. A Feminist Approach to American Fiction. Bloomington: Indiana University Press, 1978.

Fish, Stanley. "La literatura en el lector: estilística 'afectiva"”. Estética de la recepción. Ed. Rainer Warning. Madrid: Visor, 1989. 111-131.

Is There a Text in This Class? The Authority of Interpretative Communities. Cambridge: Harvard University Press, 1980.

Foucault, Michel. “¿Qué es un autor?”. La invención del autor. Nuevas aproximaciones al estudio sociológico y discursivo de la figura autorial. Ed. Juan Zapata. Medellín: Universidad de Antioquia, 2014. 33-48.

La arqueología del saber. Madrid: Siglo XXI, 1983.

Fuertes, Gloria. Aconsejo beber hilo. Diario de una loca. Madrid: Torremozas, 2017.

Fuss, Diana. "Leer como una feminista". Feminismos literarios. Eds. Neus Carbonell y Meri Torras. Madrid: Arco/Libros, 1999. 127-146.

García, Miguel Ángel (ed.). A la ética por la estética. Canon, compromiso poético y antologías en España (siglos XX-XXI) [Número monográfico]. Anthropos 245 (2016).

(ed.). El compromiso en el canon. Antologías poéticas españolas del último siglo. Valencia: Tirant, 2017. 
El antólogo como autor y la interpretación de las obras escritas por mujeres...

"Historiografía, canon, compromiso: los poetas del 27 en las antologías (19321965)". El compromiso en el canon. Antologías poéticas españolas del último siglo. Ed. Miguel Ángel García. Valencia: Tirant, 2017. 15-77.

Genette, Gérard. Umbrales. México D.F.: Siglo XXI Editores, 2001.

Gilbert, Sandra M. y Susan Gubar. La loca del desván. La escritora y la imaginación literaria del siglo XIX. Madrid: Cátedra, 1998.

Guillén, Claudio. Entre lo uno y lo diverso. Introducción a la literatura comparada. Barcelona: Crítica, 1985.

Guzmán Moncada, Carlos. De la selva al jardin. Antologías poéticas hispanoamericanas del siglo XIX. México D. F.: UNAM, 2000.

Heinich, Nathalie. De la visibilitée. Excellence et singularité en régime médiatique. París: Gallimard, 2012.

Kamuf, Peggy. Signature Pieces. On the Institution of Authorship. Ithaca \& London: Cornell University Press, 1988.

Lanz, Juan José. Introducción al estudio de la generación poética española de 1968. Bilbao: Universidad del País Vasco, 2000.

Lentricchia, Frank. Después de la "Nueva Crítica”. Madrid: Visor, 1990.

Littau, Karin. Theories of Reading. Books, Bodies and Bibliomania. Cambridge: Polity Press, 2006.

Logan Cappuccio, Brenda. "Gloria Fuertes frente a la crítica". Anales de la literatura española contemporánea 18.1/2 (1993): 89-112.

López Anglada, Luis. Panorama poético español: Historia y antología (1939-1954). Madrid: Editora Nacional, 1965.

Luis, Leopoldo de. "Toco la tierra, de Ángela Figuera". Papeles de Son Armadans XXVI. LXXVIII (1962): 327-329.

Luna, Lola. Leyendo como una mujer la imagen de la Mujer. Barcelona: Anthropos, 1996.

Maingueneau, Dominique. “Escritor e imagen de autor”. Tropelías 24 (2015): 17-30.

Martens, David y Anne Reverseau. "La Littérature dévisagée. Figurations iconographiques de l'écrivain au XXe siècle". Image \& Narrative 13.4 (2012): 1-10.

Méndez Rubio, Antonio. Poesía '68. Para una historia imposible: escritura y sociedad 19681978. Madrid: Biblioteca Nueva, 2004.

Menéndez Pelayo, Marcelino. Antología de poetas líricos castellanos. Tomo I. Madrid: Librería de la viuda de Hernando y compañía, 1890.

Millett, Kate. Politica sexual. Madrid: Cátedra, 2010.

Modleski, Tania. "Feminism and the Power of Interpretation: Some Critical Readings". Feminist Studies/Critical Studies. Ed. Teresa de Lauretis. Bloomington: Indiana University Press, 1986. 121-138.

Moreno, Mari Paz. "Mujeres poetas en las antologías de posguerra: presencia, compromiso y canon". Anthropos 245 (2016): 121-140.

Payeras Grau, María. Espejos de palabra. La voz secreta de la mujer en la poesía española de posguerra (1939-1959). Madrid: UNED, 2009.

El linaje de Eva: tres escritoras españolas de postguerra, Ángela Figuera, Celia Viñas y Gloria Fuertes. Madrid: Sial, 2003. 
Penalva, Joaquín Juan. “'Un grupo de poetas amigos'. Los autores del realismo cotidiano en Veinte años de poesía española". De sombras y de sueños. Homenaje a J. M. Castellet. Ed. Eduardo A. Salas Romo. Barcelona: Península, 2001. 186-199.

Pérez Fontdevila, Aina y Meri Torras Francés. "Hacia una biografia del concepto de autor". Los papeles del autor/a. Marcos teóricos sobre la autoría literaria. Eds. Aina Pérez Fontdevila y Meri Torras Francés. Madrid: Arco/Libros, 2016. 11-51.

Pozuelo Yvancos, José María. “Teoría del canon”. Teoría del canon y literatura española. Eds. José María Pozuelo Yvancos y Rosa María Aradra Sánchez. Madrid: Cátedra, 2000. 15-140.

Prieto de Paula, Ángel Luis. Musa del 68. Claves de una generación poética. Madrid: Hiperión, 1996.

Reyes, Alfonso. La experiencia literaria. Buenos Aires: Losada, 1952.

Riera, Carme. La Escuela de Barcelona. Barcelona: Anagrama, 1988.

Romero Tobar, Leonardo. La literatura en su historia. Madrid: Arco/Libros, 2006.

Rothe, Arnold. "El papel del lector en la crítica alemana contemporánea". Estética de la recepción. Comp. José Antonio Mayoral. Madrid: Arco/Libros, 1987. 13-27.

Ruiz Casanova, José Francisco. Anthologos: Poética de la antología poética. Madrid: Cátedra, 2007.

Russ, Joanna. How to Suppress Women's Writing. Austin: University of Texas Press, 2005.

Scholes, Robert. "Reading like a Man". Men in Feminism. Eds. Alice Jardine y P. Smith. New York and London: Methuen, 1987. 204-218.

Schweickart, Patrocinio. "Leyéndo(nos) nosotras mismas". Otramente: lectura y escritura feministas. Coord. Marina Fe. México D.F.: Fondo de Cultura Económica, 1999. 112-151.

Sherno, Sylvia R. "Carnival: Death and Renewal in the Poetry of Gloria Fuertes". MLN 104.2 (1989): 370-392.

Showalter, Elaine. "La crítica feminista en el desierto". Otramente: lectura y escritura feministas. Coord. Marina Fe. México D.F.: Fondo de Cultura Económica, 1999. 75-111. "Women and the Literary Curriculum". College English 32.8 (1971): 855-862.

Spivak, Gayatri Chakravorty. "Imperialism and Sexual Difference". Oxford Literary Review 8.1-2 (1986): 225-240.

Sullà, Enric. "El debate sobre el canon literario". El canon literario. Ed. Enric Sullà. Madrid: Arco/Libros, 1998. 11-34.

Talens, Jenaro. "De la publicidad como fuente historiográfica: la generación poética española de 1970". Del franquismo a la posmodernidad. Ed. José B. Monleón. Madrid: Akal, 1995. 57-84.

Vila-Belda, Reyes. Gloria Fuertes: poesía contra el silencio. Literatura, censura y mercado editorial (1954-1962). Madrid y Frankfurt am Main: Iberoamericana, 2017.

Viñas Piquer, David. Historia de la crítica literaria. Barcelona: Ariel, 2002.

Zavala, Iris M. "Las formas y funciones de una teoría crítica feminista. Feminismo dialógico". Breve historia feminista de la literatura española (en lengua castellana). 1. Teoría feminista: discursos y diferencia. Coords. Myriam Díaz-Diocaretz e Iris M. Zavala. Barcelona: Anthropos, 2011. 27-76. 